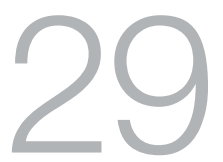

\title{
Mixed Bag of Tropical Sweets Sitting Outside the Hotel R \& R
}

\section{Audrey Brown-Pereira}

$\mathrm{n}$ is a $\mathrm{g}$ of the $\mathrm{c}$

walking peeping like his prother kaukan

whose lost in islands of imagined para-dices

panting, pounding, desperately waiting

hiding in the nut-less tree

e is still in the never never $y$

waiting 4 decisions on the unknown $\mathrm{x}$

\author{
denial \\ bereavement \\ the sensitive issue \\ yes?
}

hmmm still-awaiting the pigs 2 fly \& grow wings

$\mathrm{o}$ is an aa with gold chains and a moo-stache

(ie donkey beyond the limit+)

drinking \& driving \& driving \& drinking with balls and balls and no balls - to say stop! 
keys will fall upon graves soon

just as blood, just as time, just as day

$\mathrm{m}$ is queen $\mathrm{b}(\mathrm{jnr})$

flying upon aotearoa's wings

breathless she trips upon her uncustomary arrival

squashing the yellow tipani \& pink tipani \& white tipani in 2 pools of oil spoiled plue

mummy queen B (snr) coronates daughter queen b (jnr) with

a specially prepared \& recycled

paper cut crown

ceremonially wearing her golden lathen kikau plastic t-shirt

magnificently star studded in plack pearls \& plue pearls \& preen pearls

forming the ohh so humble words 'she came from me!'

bc brigade

march barefoot in trench coats

with their writing pads \& their writing pens \& their writing hands that do not write

accompanied by their lists of 4gotten witnesses

with their no names \& their non accounts of incidences non-4seen

inside the mixed bag of tropical sweets

sitting outside the hotel $r \& r$

white cockroaches walk \& fly \& play

as the chaos of bottomless chastity sings his vowels of virtue to the airport with no wings

kia orana! 
This text is taken from Touring Pacific Cultures, edited by Kalissa Alexeyeff and John Taylor, published 2016 by ANU Press, The Australian National University, Canberra, Australia. 